\title{
ARTICLE
}

\section{Research on long-term stability of mixed U and Pu large-sized dried (LSD) spikes for fissile material control}

\author{
Kalman Toth ${ }^{\mathrm{a}^{*}}$, Renáta Buják ${ }^{\mathrm{a}}$, Ana Maria Sánchez Hernández ${ }^{\mathrm{b}}$, Jeroen Bauwens ${ }^{\mathrm{a}}$, Ramon Carlos Marquez ${ }^{\mathrm{b}}$, Razvan \\ Buda $^{\mathrm{b}}$, Nidhu Lal Banik ${ }^{\mathrm{b}}$, Rožle Jakopič ${ }^{\mathrm{a}}$, Evelyn Zuleger ${ }^{\mathrm{b}}$ and Yetunde Aregbe ${ }^{\mathrm{a}}$ \\ European Commission, Joint Research Centre, Directorate for Nuclear Safety and Security, ${ }^{a}$ Standards for Nuclear Safety, Security \\ and Safeguards Unit, Geel, 2400, Belgium; ${ }^{b}$ Nuclear Safeguards and Forensics Unit, Eggenstein-Leopoldshafen, 76344, Germany
}

This research project aims at the application of unconventional methodologies for developing a new optimized procedure for the preparation, usage and long-term stability of actinide spike certified reference materials (CRMs). The emphasis of this research is to increase the shelf-life of large-sized dried (LSD) spikes, mixed U/Pu CRMs specifically designed for fissile material control of irradiated nuclear fuel. The IRMM-1027 series LSD spikes are applied at the two EURATOM safeguards on-site laboratories and industry worldwide. The currently used cellulose acetate butyrate (CAB) matrix wherein the nuclear material is embedded can provide life time of the spikes for around 3 years. Our investigations aimed at further enhancing $\mathrm{CAB}$ properties by using additives, or by replacing $\mathrm{CAB}$ with a more robust, longstanding matrix commonly known for its application in food industry: carboxymethyl cellulose (CMC). Further reconditioning of degraded $\mathrm{CAB}$ spikes with phosphoric acid is investigated. The use of $20-30 \%$ plasticizer additive can tremendously increase the flexibility of the coating which may lead to delayed cracking and potentially increased shelf-life. CMC spikes have remained stable for over two years and are "user-friendly". The phosphoric acid provides an easy, environmental friendly way for on-site LSD spike reconditioning. Keywords: large-sized dried (LSD) spikes; certified reference materials (CRMs); cellulose acetate butyrate
(CAB); carboxymethyl cellulose (CMC); $\mathrm{H}_{3} \mathrm{PO}_{4}$; reprocessing; IDMS

\section{Introduction}

The IRMM-1027 series of large-sized dried (LSD) spikes are tailor-made $\mathrm{U} / \mathrm{Pu}$ reference materials certified for the mass of ${ }^{235} \mathrm{U},{ }^{238} \mathrm{U}$ and ${ }^{239} \mathrm{Pu}$ per unit and the uranium and plutonium isotope amount ratios [1]. The LSD spikes are embedded into an organic layer to preserve the integrity of the dried nitrates over time. They are a fundamental part of the fissile material control of irradiated nuclear fuel at the EURATOM Safeguards on-site laboratories in Sellafield (UK) and La Hague (FR), operated by the JRC Karlsruhe, at Sellafield Ltd and at the Japanese Nuclear Fuel Limited - Rokkasho reprocessing plants. With the use of LSD spikes, no prior dilution of the input sample solution is required to prepare the blends for Isotope Dilution Mass Spectrometry (IDMS) in hot-cells or glove boxes.

The main requirements for any material that is used as the embedding matrix of actinides are: good adherence to glass, long-term mechanical stability, good resistance to radiation, ability to obtain a homogeneous actinide distribution, good solubility in hot cc. $\mathrm{HNO}_{3}$ solution. Apart from this, the material should not

*Corresponding author. Email: Kalman.toth@ec.europa.eu interfere with the chromatographic separation and mass spectrometric measurements. The currently used IRMM-1027 LSD spikes are prepared with cellulose acetate butyrate $(\mathrm{CAB})$ coating and have a shelf-life of three years. To meet the customers' needs for a longer shelf-life the JRC has engaged in a research project on the optimization of the preparation of the organic layer with embedded uranyl- and plutonium nitrate as well as investigations on new types of coatings and spikes with different $\mathrm{U} / \mathrm{Pu}$ ratios. Different approaches have been used to address these goals:

1. Improvement of the mechanical properties of the CAB film by using plasticizers.

2. Replacement of $\mathrm{CAB}$; use of foam made of carboxymethyl cellulose sodium salt (CMC) [2].

3. Reconditioning of $\mathrm{CAB}$ spikes by treatment with phosphoric acid $\left(\mathrm{H}_{3} \mathrm{PO}_{4}\right)$.

This paper aims to give a summary on present achievements to increase the shelf-life of LSD spikes.

\section{Experimental section}

\subsection{Materials}

Plutonium and uranium metals were obtained from several international laboratories [3]. Cellulose acetate 
butyrates with $35-39 \%$ (CAB-35) and with 50-54\% butyryl content (CAB-50) were purchased from Acros. Low viscosity carboxymethyl cellulose sodium salt (CMC) was acquired from Calbiochem (Merck-Millipore). Dioctyl phthalate (DIOP) was purchased from Sigma Aldrich. Ortho-phosphoric acid $\left(\mathrm{H}_{3} \mathrm{PO}_{4}\right), 85 \%$, and $\mathrm{HNO}_{3}, 65 \%$, were obtained from Merck-Millipore. Acetone, $\geq 99.0 \%$, was purchased from BDH Chemicals. All solvents and chemicals were used without further purification.

\subsection{LSD spike preparation}

A mother solution was prepared by dissolving the natural, enriched uranium and plutonium metals in hydrochloric and nitric acid. The solution was dispensed into individual penicillin vials by means of an automated system, carefully dried at $\sim 50^{\circ} \mathrm{C}$ before the coating was applied. Each unit of the IRMM-1027 series LSD spikes contains about $55 \mathrm{mg}$ of uranium with a relative mass fraction $\mathrm{m}\left({ }^{235} \mathrm{U}\right) / \mathrm{m}(\mathrm{U})$ of $18 \%$ and about $2 \mathrm{mg}$ of plutonium with a relative mass fraction $\mathrm{m}\left({ }^{239} \mathrm{Pu}\right) / \mathrm{m}(\mathrm{Pu})$ of $98 \%$ [3]. Most statements in this text refer to the IRMM-1027 series LSD spikes unless otherwise noted.

In case of the $\mathrm{CAB}$ spikes, a $10 \mathrm{wt} \%$ acetone solution was applied on the top of the dried active material and the solvent evaporated slowly in 2-3 hours. Yellow transparent films were obtained where the $\mathrm{U} / \mathrm{Pu}$ was embedded into the CAB matrix.

For the CMC spikes, first the CMC (10 wt\%) was dissolved in $\sim 2.5 \mathrm{M} \mathrm{HNO}_{3}$ solution at $\sim 65-70^{\circ} \mathrm{C}$ under continuous stirring. This solution was then dispensed into the individual vials that contained the dried $\mathrm{U} / \mathrm{Pu}$ nitrates and dried at $\sim 50-55^{\circ} \mathrm{C}$. Yellow foams of about $1.5-2 \mathrm{~cm}$ height were obtained upon drying.

$\mathrm{H}_{3} \mathrm{PO}_{4}$ spikes were prepared by adding $1.5 \mathrm{~mL}, 1 \mathrm{M}$ $\mathrm{H}_{3} \mathrm{PO}_{4}$ into each individual vial and drying it down at $80-120^{\circ} \mathrm{C}$ by gradually increasing the temperature. Yellow, transparent and glassy looking spikes were obtained.

Reconditioning of old CAB coated spikes was also made with phosphoric acid. In this case there was either a preliminary step where the remaining organic matrix was first destroyed with $2-3 \mathrm{~mL}, 8 \mathrm{M} \mathrm{HNO}$ before the $\mathrm{H}_{3} \mathrm{PO}_{4}$ was applied (two-step procedure) or the process was exactly the same as for the $\mathrm{H}_{3} \mathrm{PO}_{4}$ spike preparation as previously described (one-step procedure). The products were greenish, transparent glassy looking spikes and $\sim 1 \mathrm{~cm}$ high, dark brown-black foams, respectively.

\subsection{Instruments and techniques}

\subsubsection{IDMS}

The $\mathrm{Pu}$ amount content in IRMM-1027 LSD spikes was determined by IDMS on a Triton Thermal ionization mass spectrometer (TIMS) using IRMM-046b mixed U/Pu spike. Prior to the isotopic measurement a chemical separation of the uranium and plutonium was performed on anion exchange column (Bio Rad AG
1-X4, 100-200 mesh) [4]. Eventually, the separation method will be performed on UTEVA resin too.

\subsubsection{Tensile test}

Stress-strain traces were generated by an Instron Model 5565 Universal Tester with $5 \mathrm{kN}$ load cell according to ISO 527 (2012) standard. A bench top die (type 5B) was used to cut dumbbell shaped specimens from cast films. Samples (12 mm long, $2 \mathrm{~mm}$ width at the neck) were tested at a crosshead speed of $1 \mathrm{~mm} / \mathrm{min}$. Averages of 8-10 measurements are reported.

\subsubsection{TEM}

The samples were studied by a model FEI Tecnai G2 transmission electron microscope (TEM), equipped with a GATAN Tridiem camera and a Gatan Imaging Filter. Field emission gun was operated at $200 \mathrm{kV}$. The TEM has been adapted to study highly active or irradiated nuclear materials owing to a flange that has been inserted in the octagon hosting the objective lenses, and a glove box mounted on this flange around the compustage. Thus, the sample can be moved from the glove box where it was prepared to the microscope making the use of a La Calhène DPTE ${ }^{\circledR}$ system. The samples were prepared by the crushing method, as described in previous works [5].

\section{Results and discussion}

\subsection{CAB spikes}

$\mathrm{CAB}$ is a polymer made of repeating anhydroglucose units that are functionalized with hydroxyl-, acetyl- and butyryl- groups. It has been used as a coating material of LSD spikes for more than 15 years [6].

Recently, JRC-Geel in cooperation with the University of Ghent investigated the properties of commercially available CABs with various hydroxyl/acetyl/butyryl group ratio and different molecular weights. As a result of this study it has been shown that a mixture of CABs with varied functional group ratio but with high $\mathrm{CAB}-35$ content may be advantageous for the long-term stability of LSD spikes [7].

$\mathrm{CAB}$ is a strong material; its mechanical strength is comparable to materials that are used as artificial bone components but it lacks flexibility and easily becomes brittle. Once the CAB starts to degrade, either due to chemical or radiochemical processes, it becomes less flexible and eventually the mechanical strength drops too. In case of the LSD spikes it leads to crack formations, chipping and flaking after about 3 years from the time of production. Plasticizers are well known polymer additives that are commonly used to increase flexibility and durability, lower $\mathrm{T}_{\mathrm{g}}$ or influence other physical properties. The effects of 10, 20 and $30 \mathrm{wt} \%$ (relative to the CAB) DIOP plasticizer on the static mechanical properties of solvent cast films were investigated (Table 1). Either CAB-35 or a 9:1 mixture of CAB-35 and CAB-50 was used, the addition of 20 or $30 \%$ DIOP plasticizer led to tremendously improved 
elongation. While the polymer or polymer mixture initially shows only $\sim 4 \%$ tensile strain with the addition of $30 \%$ DIOP this value can be increased to up to $40-45 \%$. At the same time, the tensile strength loss is modest (typically less than 25\%) and the residual 25-30 MPa mechanical strength is still much higher than what is required for this application. These results are in reasonably good agreement with the findings of other research groups [8]. Whether or not plasticizer is added, the $\mathrm{CAB}$ degradation starts from the moment the polymer coated spike is prepared however, with the refined initial stress-strain values the embrittlement and flaking of the LSD spikes may be delayed which could lead to an extended shelf-life.

Table 1. Stress-strain data of a) CAB-35 films and b) CAB-35/CAB-50 9/1 with different plasticizer (DIOP) content between 0 and $30 \mathrm{wt} \%$.

\begin{tabular}{|c|c|c|}
\hline Composition & $\begin{array}{c}\text { Tensile } \\
\text { strength }(\mathbf{M P a})\end{array}$ & $\begin{array}{c}\text { Tensile strain } \\
\mathbf{( \% )}\end{array}$ \\
\hline $\mathrm{CAB}-35$ & $40.0 \pm 6.6$ & $4.1 \pm 0.7$ \\
\hline $\mathrm{CAB}-35+10 \%$ DIOP & $38.1 \pm 1.4$ & $9.0 \pm 1.7$ \\
\hline $\mathrm{CAB}-35+20 \%$ DIOP & $37.3 \pm 3.1$ & $34.5 \pm 5.1$ \\
\hline $\mathrm{CAB}-35+30 \%$ DIOP & $31.4 \pm 2.3$ & $43.8 \pm 6.0$ \\
\hline $\mathrm{CAB}-35 / 50^{*}$ & $39.4 \pm 9.0$ & $4.0 \pm 1.7$ \\
\hline $\begin{array}{c}\mathrm{CAB}-35 / 50^{*}+10 \% \\
\text { DIOP }\end{array}$ & $34.9 \pm 0.9$ & $12.4 \pm 2.8$ \\
\hline $\begin{array}{c}\mathrm{CAB}-35 / 50^{*}+20 \% \\
\text { DIOP }\end{array}$ & $34.5 \pm 4.5$ & $31.1 \pm 10.0$ \\
\hline $\begin{array}{c}\mathrm{CAB}-35 / 50^{*}+30 \% \\
\mathrm{DIOP}\end{array}$ & $26.4 \pm 5.1$ & $39.3 \pm 12.1$ \\
\hline
\end{tabular}

\subsection{CMC spikes}

CMC is, similarly to $\mathrm{CAB}$, also built up from repeating anhydroglucose units but this cellulose derivative is functionalized with carboxymethyl groups, which are converted into a sodium salt. These differences make CMC insoluble in most organic solvents, including acetone that is used for $\mathrm{CAB}$ spike preparation. For this reason, the CMC was prepared in $\mathrm{HNO}_{3}$ solution and instead of a polymer film, a foam was created in which the actinides were homogeneously embedded, as proven by SEM-EDX [2]. One of the valuable properties of the CMC spikes is that it almost instantly dissolves in hot $\mathrm{HNO}_{3}$ which facilitates the work of the hot-cell operator.

CMC has high complexation capacity that allows the production of spikes with different $\mathrm{U} / \mathrm{Pu}$ ratios using large amounts of nuclear material. Spikes with U/Pu ratio of 100 containing as much as $200 \mathrm{mg}$ of $U$ and 2 $\mathrm{mg}$ of $\mathrm{Pu}$ were produced. Over time, CMC spikes can undergo discoloration and the pores of the foam can enlarge but so far the spikes with the $\mathrm{Pu}, \mathrm{U}$ and mixed $\mathrm{U} / \mathrm{Pu}$ embedded in $\mathrm{CMC}$ have not shown any sign of chipping or flaking.

Additional TEM analyses have been performed on CMC foam with nuclear material with $\mathrm{U} / \mathrm{Pu}$ ratio $\sim 20$ ( $2 \mathrm{mg} \mathrm{Pu}$ ). It shows a perfectly amorphous material, with no rings or single diffraction spots which could be assigned to any crystallinity (see Figure 1).

A few particles were also found that were not perfectly amorphous (image not shown). When higher resolution was used, and although the nanocrystalline structure could not be observed directly, the electron diffraction showed clear rings, which fit perfectly with a face-centered cubic structure, coincident with the structure of the $\mathrm{UO}_{2}$.
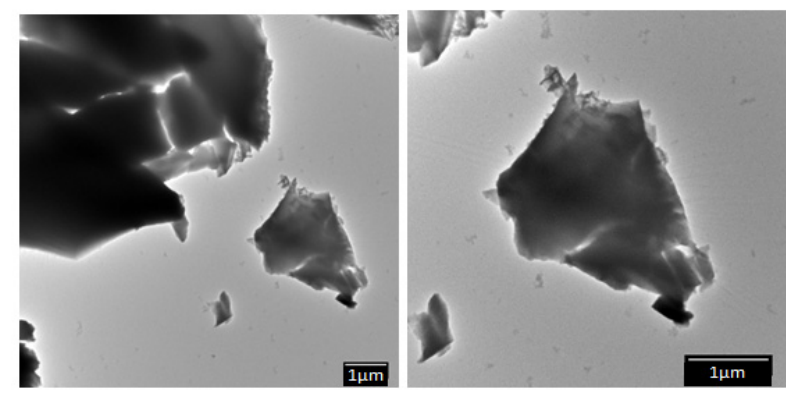

Figure 1. Low resolution bright field images of typical particles on the $\mathrm{CMC}-\mathrm{U} / \mathrm{Pu}$ material.

\section{3. $\mathrm{H}_{3} \mathrm{PO}_{4}$ spikes and reconditioning old spikes}

Phosphoric acid was also investigated as alternative coating matrix for actinides. When $\mathrm{H}_{3} \mathrm{PO}_{4}$ was applied on dried $\mathrm{U} / \mathrm{Pu}$ a yellow amorphous spike was produced (Figure 2a). This product had a tendency to become a viscous liquid after 1-2 months of storage due to the fact that phosphoric acid absorbs water from the environment. This property makes $\mathrm{H}_{3} \mathrm{PO}_{4}$ less attractive for large scale production of LSD spikes. Nonetheless, it could be an appealing option for on-site reconditioning of degraded CAB spikes.

The combined degradation effects lead to discoloration, crack formation, finally flaking of CAB coated LSD spikes and a potential loss of a material upon opening the vial at which point the certified values cannot be guaranteed any more. This approach is beneficial for the reconditioning of the spikes that are already in stock at the facility before they start to flake and therefore to prolong their shelf-life. The product obtained with the two-step procedure (Figure 2b) has a tendency to become a viscous liquid after 1-2 months of storage. Nonetheless, as flaking is not expected to occur, there is less chance for the active material to 'escape' and this spike if handled properly could be used for many years. Moreover, it can be heated up again before use or in case of a need to recreate the amorphous solid form. With the selected phosphoric acid concentration the most likely formed products are: $\mathrm{UO}_{2} \mathrm{HPO}_{4} \times 4 \mathrm{H}_{2} \mathrm{O}$ and $\mathrm{Pu}\left(\mathrm{HPO}_{4}\right)_{2} \times \mathrm{xH}_{2} \mathrm{O}$ (although at higher temperature an oxidation state change of $U$ and/or Pu might occur) [9]. The structure will be further investigated by X-Ray Diffraction (XRD) and UV-Vis.

The main advantages of one-step procedure (Figure 2c) are that it takes only a few hours to prepare and the acid remains in the vial. This procedure can be applied in laboratories with stringent regulations related to applicable solvents and acid evaporation. The foam is 
stable for at least six months and its long-term stability is still under investigation.

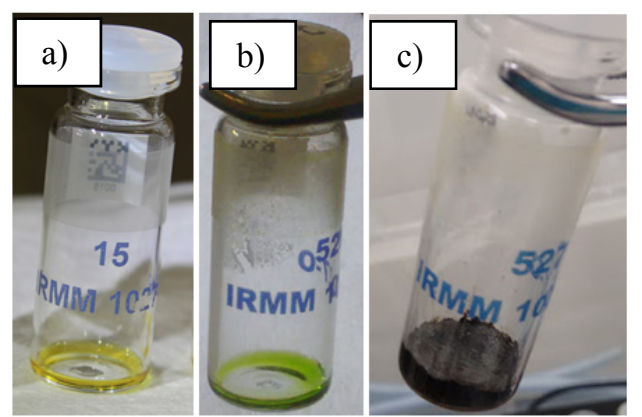

Figure 2. a) Phosphoric acid spike b) CAB spike reconditioned with the two- and c) one-step procedures.

\section{4. ${ }^{239} \mathrm{Pu}$ verification}

The verification results of the ${ }^{239} \mathrm{Pu}$ amount content in $\mathrm{H}_{3} \mathrm{PO}_{4}$ and $\mathrm{CMC}$ covered LSD spikes can be seen on Figure 3. The results of all of the measured spikes were within measurement uncertainty and we can conclude that no significant interferences during $\mathrm{U} / \mathrm{Pu}$ separation or mass spectrometry measurements have been observed.

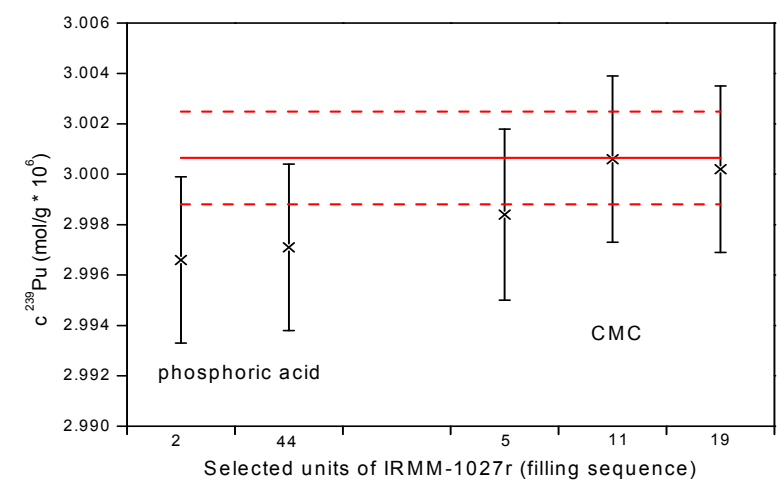

Figure 3. Verification results of ${ }^{239} \mathrm{Pu}$ amount content in $\mathrm{H}_{3} \mathrm{PO}_{4}$ and CMC covered LSD spikes.

Nonetheless, the chemical separation process may need to be optimized for phosphoric acid spikes, which will be done in a separate study.

\section{Conclusion}

The research carried out at the JRC gives strong evidence that dried $\mathrm{U} / \mathrm{Pu}$ but possibly also other actinide materials, including CRMs, can be preserved for more than 3 years without the disintegration of the matrix the actinides are embedded in. The CAB coated spikes show improved flexibility when plasticizer is added which may eventually lead to delayed cracking and flaking. The foreseeable long-term stability and instant solubility of CMC spikes makes them very promising candidates towards increased long-term stability. The phosphoric acid can be applied for on-site reconditioning of older spike CRMs which can also result in extended certificate validity.

\section{Acknowledgements}

The authors wish to thank Stephan Richter (JRC-Geel, Geel, Belgium) for IDMS measurements, the group of Thierry Wiss (JRC-Karlsruhe, Karlsruhe, Germany) for TEM analysis, Laurens Delva and Ludwig Cardon (CPMT, University of Ghent, Belgium) for tensile testing.

\section{References}

[1] R. Jakopič, Y. Aregbe, S. Richter, E. Zuleger, S. Mialle, S.D. Balsley, U. Repinc and J. Hiess, Verification measurements of the IRMM-1027 and the IAEA large-sized dried (LSD) spikes, $J$. Radioanal. Nucl. Chem. 311 (2017), pp. 1781-1791.

[2] R. Carlos, R. Buda, K. Lützenkirchen, A.S. Hernández and van P. Belle, Stabilisation of uranium/plutonium dried spikes with a cellulose matrix, Proceedings of 37th ESARDA Symposium on Safeguards and Nuclear Non-Proliferation, Manchester, UK, (2015), pp 498-505.

[3] R. Jakopic, J. Bauwens, R. Bujak, C. Hennessy, F. Kehoe, U. Jakobsson, S. Richter and Y. Aregbe, Certification report: preparation and certification of large-sized dried (LSD) spike - IRMM-1027r, EUR 28081 EN (2016) ISBN: 978-92-79-61458-3.

[4] R. Jakopič, A. Verbruggen, R. Eykens, F. Kehoe, H. Kühn, Y. Kushigeta, U. Jacobsson, J. Bauwens, S. Richter, R. Wellum and Y. Aregbe, An inter-calibration campaign using various selected $\mathrm{Pu}$ spike isotopic reference materials, J. Radioanal. Nucl. Chem. 286 (2010), pp. 449-454.

[5] T. Wiss, O. Dieste-Blanco, A. Tacu, A. Janssen, Z. Talip and J.-Y. Colle, TEM study of alpha-damaged plutonium and americium dioxides, J. Mater. Res., 30 (2015), pp. 1544-1554.

[6] N. Surugawa, T. Hiyama, A. Verbruggen and R. Wellum, Preparation, certification and validation of stable solid spike of uranium and plutonium coated with a cellulose derivative for the measurement of uranium and plutonium content in dissolved nuclear fuel by dilution mass spectrometry. Anal. Sci. 24 (2008), pp. 247-252.

[7] R. Buják, L. Delva, M. Erkoç, J. Bauwens, R. Jakopič, L. Vincze, Y. Aregbe and L. Cardon, Long-term stability of cellulose acetate butyrate thin films for nuclear certified reference materials, J. Radioanal. Nucl. Chem. 311 (2017), pp. 877-886.

[8] P. Wojciechowska, The effect of concentration and type of plasticizer on the mechanical properties of cellulose acetate butyrate organic-inorganic hybrids, Recent Advances in Plasticizers, Dr. Mohammad Luqman (Ed.), (2012), pp. 141-164, ISBN: 978-953-51-0363-9, InTech.

[9] a) V. Vesely, V. Pekarek and M. Abbrent, J. Inorg. Nucl. Chem. 27 (1965), pp. 1159-1166; b) L.R. Morss, N. Edelstein and J. Fuger, (Eds.), The Chemistry of the Actinide and Transactinide Elements; 4th ed., Sprieger, (2010). 